\title{
Bioinformatics analysis on multiple Gene Expression Omnibus datasets of the hepatitis $B$ virus infection and its response to the interferon-alpha therapy
}

Zebin Zhu $u^{1,2 \dagger}$, Shanzhou Huang ${ }^{2,3 \dagger}$, Yixi Zhang ${ }^{2,4,5 \dagger}$, Chengjun Sun ${ }^{2,4,5}$, Yunhua Tang ${ }^{2,4,5}$, Qiang Zhao ${ }^{2,4,5}$, Qi Zhou $2,6,7^{*}$, Weiqiang Ju $\mathrm{J}^{2,45^{*}}$ and Xiaoshun $\mathrm{He}^{2,4,5^{*}}$

\begin{abstract}
Background: Hepatitis B virus (HBV) infection is a global health problem and interferon-alpha (IFN-a) is one of the effective therapies. However, little is known about the genetic background of the HBV infection or the genetic determinants of the IFN-a treatment response. Thus, we aim to explore the possible molecular mechanisms of HBV infection and its response to the IFN-a therapy with a comprehensive bioinformatics analysis.

Methods: The Gene Expression Omnibus datasets (GSE83148, GSE84044 and GSE66698) were collected and the differentially expressed genes (DEGs), key biological processes and intersecting pathways were analyzed. The expression of the co-expressed DEGs in the clinical samples was verified by quantitative real time polymerase chain reaction (qRT-PCR).

Results: Analysis of all the 3 datasets revealed that there were eight up-regulated and one down-regulated coexpressed DEGs following the HBV infection and after IFN-a treatment. In clinical samples, the mRNA level of HKDC1, EPCAM, GSN, ZWINT and PLD3 were significantly increased, while, the mRNA level of PLEKHA2 was significantly decreased in HBV infected liver tissues compared to normal liver tissues. PI3K-Akt signaling pathway, focal adhesion, HTLV-I infection, cytokine-cytokine receptor interaction, metabolic pathways, NF-KB signaling pathway were important pathways associated with the HBV infection and the response of IFN-a treatment.

Conclusions: The co-expressed genes, common biological processes and intersecting pathways identified in the study might play an important role in HBV infection and response of IFN-a treatment. The dysregulated genes may act as novel biomarkers and therapeutic targets for HBV.
\end{abstract}

Keywords: Hepatitis B virus, Bioinformatics analysis, Differentially expressed gene

\section{Background}

Hepatitis B virus (HBV) infection is one of the most common and serious infectious diseases in the world [1]. Chronic HBV has characteristics of high morbidity and are hard-to-heal; HBV-related hepatitis has lots of adverse impact on the patients' quality of life, even causing

\footnotetext{
* Correspondence: hnzhouqi@163.com; weiqiangju@163.com;

1107123962@qq.com

'Zebin Zhu, Shanzhou Huang and Yixi Zhang contributed equally to this work.

${ }^{2}$ Organ Transplant Center, The First Affiliated Hospital, Sun Yat-sen University, No. 58 Zhongshan Er Road, Guangzhou 510080, Guangdong, China Full list of author information is available at the end of the article
}

death of the patients. At present, more than 240 million individuals, worldwide, are infected with chronic HBV. Amongst the untreated individuals with chronic HBV infection, 15 to $40 \%$ progress to cirrhosis, which may lead to liver failure or hepatic carcinoma [2]. The more serious problem is that $25 \%$ of individuals who acquire HBV as children develop primary cirrhosis or hepatic carcinoma as adults [3]. As HBV infection is ranked as the top health priorities of the world, the world health organization (WHO) has included viral hepatitis as its major public health priorities [4].

(c) The Author(s). 2020 Open Access This article is distributed under the terms of the Creative Commons Attribution 4.0 International License (http://creativecommons.org/licenses/by/4.0/), which permits unrestricted use, distribution, and 
Chronic HBV infection is known to cause an immunemediated liver damage which progresses to cirrhosis and hepatocellular carcinoma (HCC). Although vaccine and antiviral therapies have been used for some decades, the HBV infections were not thoroughly cured. Thus, it is crucial to study more about the underlying biological mechanisms of the progression of $\mathrm{HBV}$ infection. Interferon-alpha (IFN- $\alpha$ ) has been the first-line of treatment for chronic HBV infection for decades due its low rates of drug resistance and high rates of HBsAg seroclearance. However, only $30-40 \%$ of the chronic HBV patients benefits from the IFN- $\alpha$ therapy [5]. Studies have shown that genetic variations of the host may provide new approaches to predict responses to the IFN- $\alpha$ based therapy [6]. Therefore, it is critical to discover predictors for the outcomes of IFN- $\alpha$ treatment to improve the personalized therapy for the chronic HBV patients.

Gene profiling analyses have been used as a common method to identify the molecular mechanisms underlying the progression of diseases. Several studies [7-9] have used the gene array technologies to report different identifying factors involved in the HBV-related hepatic diseases. However, there are only a few studies about the relationship of HBV infection with gene expression profiling. In an attempt to explore the molecular mechanisms of HBV infection and discover predictors for outcomes of IFN- $\alpha$ treatment, we carried out a comprehensive bioinformatics analysis of the HBV infected and normal liver tissues, responders before and after the IFN$\alpha$ treatment on the Gene-Cloud of Biotechnology Information (GCBI) bioinformatics platform. Subsequently, based on the comprehensive bioinformatics analysis, we determined several key differentially expressed genes (DEGs), biological processes and pathways that are closely associated with the HBV infection and response to the IFN- $\alpha$ treatment. Moreover, to validate the reliability of the microarray data, the expression of the DEGs was assessed by quantitative real time polymerase chain reaction (qRT-PCR) in the clinical samples.

\section{Methods}

\section{Gene Expression Omnibus (GEO) datasets}

GEO (https://www.ncbi.nlm.nih.gov/gds) is a public repository at the National Center of Biotechnology Information (NCBI) for storing data generated from highthroughput microarray experiments. We selected potential GEO datasets according to the following inclusion criteria: 1) specimens with histological diagnosis; 2) human liver tissues diagnosed as HBV-positive were used as the experimental group; 3 ) normal liver tissues (HBVnegative) used as controls; and 4) supported by GCBI analysis laboratory. And the exclusion criteria as follows: 1) data generated from other organisms; 2) expression profiling by qRT-PCR (or genome variation profiling by
SNP array/SNP genotyping by SNP array); 3) analyses on platforms other than GPL570 or 4) sample size $<10$.

We used the search terms "HBV infection" $[\mathrm{MeSH}$ Terms] and "Homo sapiens" [Organism] and "CEL" [Supplementary Files] and "Expression profiling by array" [DataSet Type] in the GEO datasets to determine potential datasets. Then, all the searched datasets were screened carefully according to the above inclusion and exclusion criteria. Finally, 3 GEO datasets, GSE83148, GSE84044 and GSE66698 were included in the present study.

\section{GCBI}

GCBI (Shanghai, China, https://www.gcbi.com.cn) is a powerful platform that provides comprehensive bioinformatics analysis, and it can create a "gene knowledge base," which involves GEO datasets. GCBI platform can systematically analyze GEO dataset-derived gene expression information, including more than 120 million copies of genomic samples [10]. In our study, GCBI was used to identify DEGs between the HBV infected and normal liver tissues, liver biopsy samples of IFN- $\alpha$ responders before and after treatment. In the DEG analysis module provided by the GCBI platform, DEGs with a fold expression change $>2$ at cut-off values $\mathrm{Q}<0.05$ and $P<0.05$ were identified. Venn diagrams were used to compare the top 50 DEGs from 3 cohorts by Venny (http://bioinfogp.cnb.csic.es/tools/venny/index.html).

Based on the DEGs, biological functions were studied by means of gene ontology (GO) analysis and biochemistry pathways were evaluated by Kyoto Encyclopedia of Genes and Genomes (KEGG) analysis. The top 20 biological functions and signaling pathways are presented. Additionally, the core networks and pathway connections were identified using a pathway relation network module. Therefore, to determine the core genes in the networks, we utilized the Gene Co-expression Network module on the GCBI platform to construct gene coexpression networks for the DEGs. The significant GO biological process terms and KEGG pathways for the identified DEGs were evaluated using the Database for Annotation, Visualization, and Integrated Discovery (DAVID) and the WEB-based GEne SeT AnaLysis Toolkit (WebGestalt). For GO, KEGG and co-expression network analysis, the $P<0.05$ threshold was used to determine statistical significance.

\section{Gene signal network analysis}

Many studies have shown that the expression of genes is affected by one another. This interactive and mutually restrictive relationship constitutes a complex network of gene expression and regulation. Therefore, a gene's upstream or downstream genes could be obtained by a gene signal network analysis of the entire KEGG pathway database. In the present study, we performed gene 
signal network analysis (GCBI Analyzing Lab) by using the GCBI platform (https://www.gcbi.com.cn/gclab/ html/index) to determine hub genes. For gene signal network analysis, the $P<0.05$ threshold was used to determine statistical significance.

\section{Tissue specimens, RNA extraction and qRT-PCR analysis}

Ten normal liver tissues from the HBV-negative donor livers and $15 \mathrm{HBV}$-positive liver tissues from patients with HBV related hepatic cirrhosis were enrolled in our study to validate the expression levels of co-expressed DEGs.

Additional file 1: Table S1 shows the clinical characteristic of the 10 donors and 15 patients who underwent liver transplantation in detail. Prior patient consent and ethical approval from the ethics committee of The First Affiliated Hospital of Sun Yat-sen University were obtained. In accordance with the ethics guidelines and regulations, all methods were performed. We validated the 8 up-regulated co-expressed DEGs, including RRM2, HKDC1, EPCAM, GSN, CXCR4, MTHFD2, ZWINT, PLD3 and 1 down-regulated co-expressed DEG (PLEKHA2). HBV infection was diagnosed based on the patient's laboratory testing results as being "HBsAg positive", "HBV DNA positive" or "both positive". Total RNA from the liver tissue specimens was extracted using the TRIzol reagent (Invitrogen, Carlsbad, California, USA), and qRT-PCR was performed with the SYBR $^{\circ}$ Green dye (TaKaRa, Shiga, Japan), following the manufacturer's instructions. The primer sequences are provided in Additional file 2: Table S2. $\beta$-tubulin was used as a reference gene.

\section{Statistical analysis}

Data are presented as the mean \pm standard deviation for continuous variables. Analysis of variance and Student's $t$-test were used to compare the differences between the groups. Analyses were carried out by the Statistical Package for the Social Science (SPSS) for Windows, version 22.0 (IBM, USA). Results were considered significant when a $P$ value was less than 0.05 and all $P$ values were two-sided.

\section{Results \\ Study design}

The flow chart of our study design is shown in Fig. 1. Our initial aim was to identify the core genes involved in the development of HBV infection. Using the 3 GEO datasets (GSE83148, GSE84044 and GSE66698) in the GCBI bioinformatics analysis platform, we extracted the gene expression data of the HBV infected and normal liver tissues to identify the DEGs. The co-expressed DEGs were identified from these 3 cohorts. Then, we verified the mRNA expression of the co-expressed DEGs in the clinical samples to confirm the results of the microarray analysis. The biological function and KEGG pathway analyses were performed on the 3 datasets. Moreover, we performed the gene signal network and gene co-expression network analyses to identify the gene connections between the different genes.

Basic characteristics of samples in 3 datasets GEO datasets GSE83148 (Cohort 1), GSE84044 (Cohort 2) and GSE66698 (Cohort 3) were used for the bioinformatics

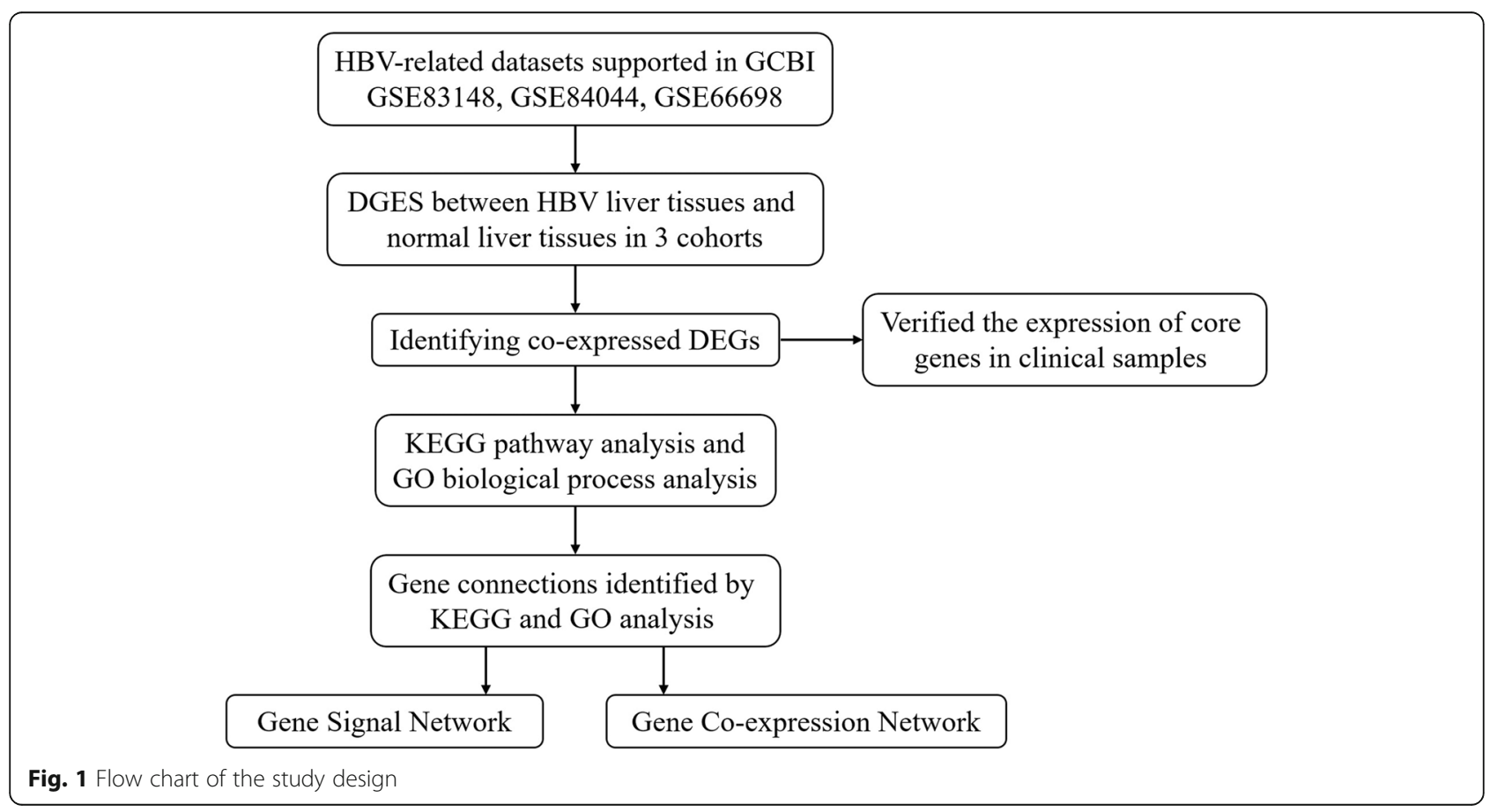


analysis of our study. Cohort 1 [11] contained $122 \mathrm{HBV}$ infected and 6 normal liver tissues; the HBV infected liver samples were validated by positive HBsAg or serum HBVDNA. Cohort 2 [12] contained 124 HBV infected and 6 normal liver tissues. All patients were diagnosed on the basis of the criteria recommended by the Asian Pacific Association for the Study of the Liver [13]. Cohort 3 [14] included 7 paired liver biopsy samples of the IFN- $\alpha$ responders before/after treatment and 3 other pretreatment samples. All the 3 datasets were available in the GCBI bioinformatics analysis platform.

DEGs of the HBV infected and normal liver tissues, liver biopsy samples of the IFN- $\alpha$ responders before and after treatment

We identified 775, 742, and 2200 potential DEGs in GSE83148, GSE84044 and GSE66698 datasets, respectively (Fig. 2a-c). Table 1 shows the top 10 DEGs of the 3 cohorts. After removing the duplicate genes and expression values lacking specific gene symbols, we used the top 50 DEGs from GSE83148, GSE84044 and GSE66698 datasets to create a Venn diagram. The intersection of these 3 datasets in Fig. 3 shows that RRM2, HKDC1, EPCAM, GSN, CXCR4, MTHFD2, ZWINT, PPLD3 were the upregulated co-expressed DEGs, and PLEKHA2 was the down-regulated co-expressed DEG in all the 3 cohorts. Every 2 datasets were checked for intersection for common genes, viz., SOX4 was co-expressed in Cohort 1 and Cohort 3; and the CBS gene co-expressed in Cohort 2 and Cohort 3; while, 36 other genes co-expressed in Cohort 1 and Cohort 2.

\section{Validation of the expression of the core genes in the clinical samples}

To determine which genes correlated with the HBV infection, we used qRT-PCR to detect the expression of 9 DEGs in 15 liver samples of the liver transplantation patients. Ten liver samples from donors (HBV-negative) were used as controls. We found that the mRNA expression of HKDC1, EPCAM, GSN, ZWINT and PLD3 was significantly increased in the HBV infected liver samples compared to the normal liver samples (Fig. 4b-d, g-h, $P<0.05$ for all), and the mRNA expression of PLEKHA2 was significantly decreased (Fig. $4 \mathrm{i}, P<0.001$ ); these findings are consistent with the results of the bioinformatics analysis done above. However, there was no statistically significant difference in the expression of RRM2, CXCR4 and MTHFD2 between the HBV infected and the normal liver samples (Fig. 4a, e-f, $P>0.05$ ).

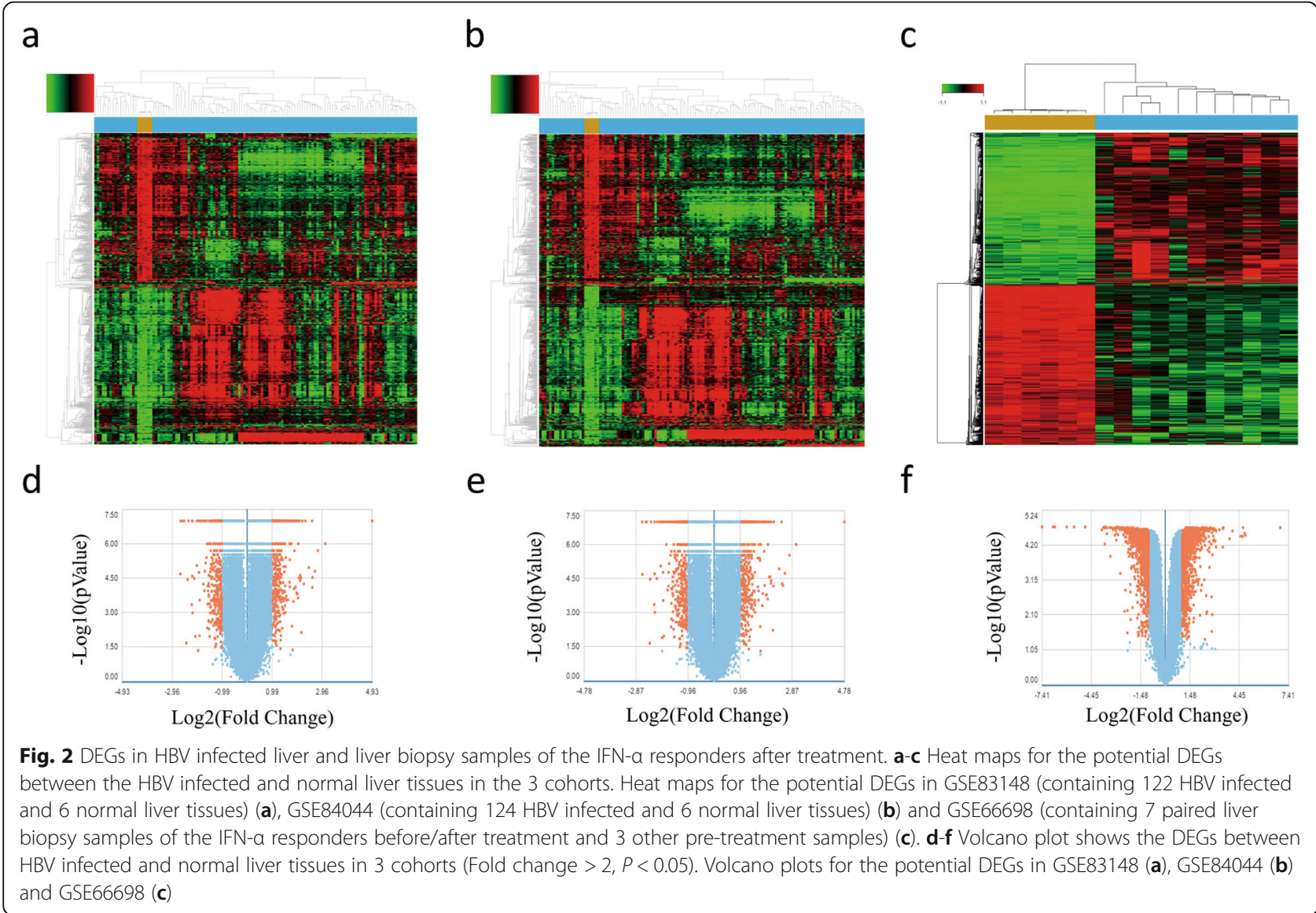


Table 1 Top 10 differentially expressed genes in 3 cohorts

\begin{tabular}{|c|c|c|c|c|}
\hline Rank & Probe set ID & Gene symbol & Gene description & Regulation \\
\hline \multicolumn{5}{|c|}{ Cohort 1} \\
\hline 1 & 224588_at & XIST & $X$ inactive specific transcript & up \\
\hline 2 & 239380_at & C5orf27 & chromosome 5 open reading frame 27 & down \\
\hline 3 & 203032_s_at & $\mathrm{FH}$ & fumarate hydratase & down \\
\hline 4 & 238013_at & PLEKHA2 & pleckstrin homology domain containing, family A, member 2 & down \\
\hline 5 & 201909_at & RPS4Y1 & ribosomal protein S4, Y-linked 1 & down \\
\hline 6 & 209773_s_at & RRM2 & ribonucleotide reductase $\mathrm{M} 2$ & up \\
\hline 7 & 220116_at & KCNN2 & small conductance calcium-activated channel subfamily N member 2 & down \\
\hline 8 & 227614_at & HKDC1 & hexokinase domain containing 1 & up \\
\hline 9 & 1555175_at & PBLD & phenazine biosynthesis-like protein domain containing & down \\
\hline 10 & 204409_s_at & EIF1AY & eukaryotic translation initiation factor $1 \mathrm{~A}, \mathrm{Y}$-linked & down \\
\hline \multicolumn{5}{|c|}{ Cohort 2} \\
\hline 1 & 239380_at & C5orf27 & chromosome 5 open reading frame 27 & down \\
\hline 2 & 203032_s_at & $\mathrm{FH}$ & fumarate hydratase & down \\
\hline 3 & 224588_at & XIST & X inactive specific transcript (non-protein coding) & up \\
\hline 4 & 238013_at & PLEKHA2 & pleckstrin homology domain containing, family A, member 2 & down \\
\hline 5 & 201909_at & RPS4Y1 & ribosomal protein S4, Y-linked 1 & down \\
\hline 6 & 209773_s_at & RRM2 & ribonucleotide reductase $\mathrm{M} 2$ & up \\
\hline 7 & 220116_at & KCNN2 & small conductance calcium-activated channel subfamily N member 2 & down \\
\hline 8 & 1555175_at & PBLD & phenazine biosynthesis-like protein domain containing & down \\
\hline 9 & 227614_at & HKDC1 & hexokinase domain containing 1 & up \\
\hline 10 & 204409_s_at & EIF1AY & eukaryotic translation initiation factor $1 \mathrm{~A}, \mathrm{Y}$-linked & down \\
\hline \multicolumn{5}{|c|}{ Cohort 3} \\
\hline 1 & 223579_s_at & APOB & apolipoprotein B & up \\
\hline 2 & 227556_at & NME7 & NME/NM23 family member 7 & up \\
\hline 3 & 1558199_at & FN1 & fibronectin 1 & down \\
\hline 4 & 227621_at & WTAP & Wilms tumor 1 associated protein & up \\
\hline 5 & 217878_s_at & $\mathrm{CDC27}$ & cell division cycle 27 & down \\
\hline 6 & 229457_at & ANKHD1 & ankyrin repeat and $\mathrm{KH}$ domain containing 1 & down \\
\hline 7 & 213956_at & CEP350 & centrosomal protein $350 \mathrm{kDa}$ & up \\
\hline 8 & 212291_at & HIPK1 & homeodomain interacting protein kinase 1 & up \\
\hline 9 & 1554241_at & $\mathrm{COCH}$ & cochlin & up \\
\hline 10 & 201775_s_at & EFCAB14 & EF-hand calcium binding domain 14 & down \\
\hline
\end{tabular}

\section{Biological process analysis}

We studied the biological functions of the DEGs by using a GO analysis. The corresponding top 20 biological processes from the 3 cohorts are shown in Table 2. The biological process analysis revealed the following 11 common biological functions in the 3 cohorts, viz., "immune response" and "small molecule metabolic process" "cell adhesion", "signal transduction", "negative regulation of apoptotic process", "apoptotic process", "mitotic cell cycle", "protein phosphorylation", "axon guidance", "blood coagulation" and "negative regulation of transcription from RNA polymerase II promoter". The 6 common biological processes in Cohort 1 and Cohort 2 are inflammatory response, negative regulation of transcription (DNA-dependent), protein complex assembly, response to virus, regulation of immune response and dendritic cell chemotaxis. While, there were no common biological process either in Cohort 1 and Cohort 3 or in Cohort 2 and Cohort 3.

\section{Pathway analysis}

KEGG pathway analysis was used to investigate the signaling pathway based on the identified DEGs. Table 3 shows the top 20 pathways of the 3 cohort. Among 


\section{a}

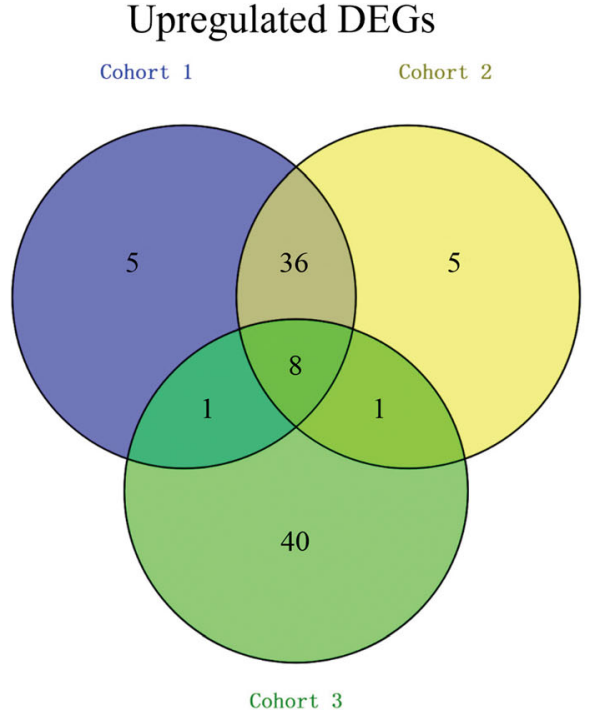

b

\section{Downregulated DEGs}

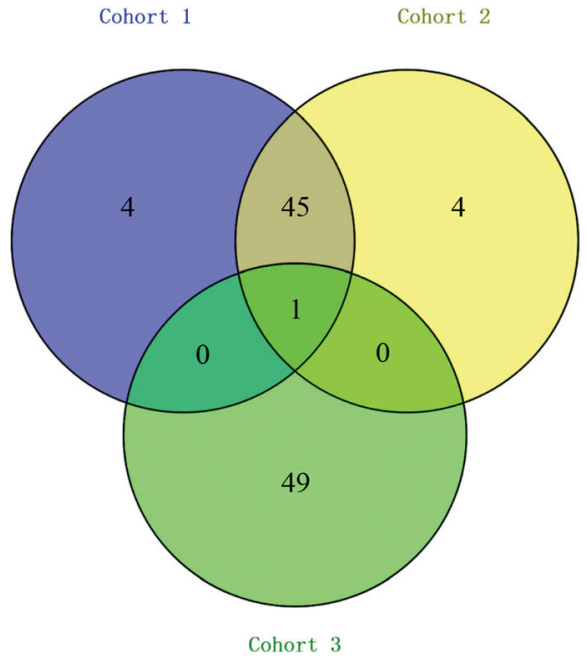

Fig. 3 The Venn diagrams show the DEGs and the co-expressed genes among the 3 cohorts. The Venn diagram shows the top 50 up-regulated DEGs and co-expressed genes amongst cohort 1 (GSE83148), cohort 2 (GSE84044) and cohort 3 (GSE66698) (a). The Venn diagram shows the top 50 down-regulated DEGs and co-expressed genes amongst the 3 cohorts (b)

them, PI3K-Akt signaling pathway, focal adhesion, HTLV-I infection, cytokine-cytokine receptor interaction, metabolic pathways, NF- $\mathrm{B}$ signaling pathway, influenza $A$ and chemokine signaling pathway were the 8 common pathways related to $\mathrm{HBV}$ infection and response of IFN- $\alpha$ treatment. In addition, extracellular matrix (ECM)-receptor interaction, cell adhesion molecules (CAMs), p53 signaling pathway, viral carcinogenesis, amoebiasis, protein digestion and absorption, proteoglycans in cancer, cell cycle and hepatitis B were the other intersecting pathways in pairwise comparisons.

\section{Gene signal network analysis}

On the basis of the interactions between the genes and the genes in KEGG database, the gene signal network analysis was constructed. In the gene signal network analysis, a total of 173, 162, 506 hub nodes (hub genes) in cohort 1 , cohort 2 and cohort 3 were identified, respectively (Fig. 5). Table 4 shows the top 10 hub genes involved in the gene signal network in each cohort. Among them, PLA2G2A, CXCR4, GNG12 and CXCL11 were the 4 common genes of the gene signal network (Fig. 7b).

\section{Gene connections and co-expression networks analyses} We picked out 173, 162 and 506 overlapped genes from cohort 1 , cohort 2 , and cohort 3 , respectively and applied them to the gene connections analysis (Fig. 6), which revealed the 5 common genes as ENO1, TDO2, CXADR, MTHFD2 and PSME3 (Fig. 7a). Table 5 shows the top 10 genes involved in the gene co-expression network in the 3 cohorts, amongst which, CD74, CCL5, CXCL10 and PTPRC were the 4 common genes (Fig. 7c). Therefore, CD74, CCL5, CXCL10 and PTPRC were the genes with the most connections in the gene coexpression network.

\section{Discussion}

Approximately, $30 \%$ of the world's population shows serological evidence of current or past HBV infection [15]. Chronic HBV infection causes immune-mediated liver damage progressing to cirrhosis and HCC [16]. Thus, early diagnosis and treatment is vital to improve the cure rates of HBV. Many genes could be associated with the susceptibility and development of $\mathrm{HBV}$ infection. Previous study reported that the low copy number of TLR7 gene is a risk factor for chronic HBV infection but is not associated with later stages of the disease progression [17]. In the present study, we extracted the gene expression data of $\mathrm{HBV}$ infected liver tissues and normal liver tissues from 3 GEO datasets on which we performed comprehensive bioinformatics analyses. Differential expression analyses in GCBI were used to identify the co-expressed DEGs, common biological processes and pathways between $\mathrm{HBV}$ infected liver tissues and normal liver tissues, liver biopsy samples of IFN- $\alpha$ responders before and after treatment.

The GCBI comprehensive analysis platform analyses revealed the following genes: RRM2, HKDC1, EPCAM, GSN, CXCR4, MTHFD2, ZWINT, PLD3 were the up- 

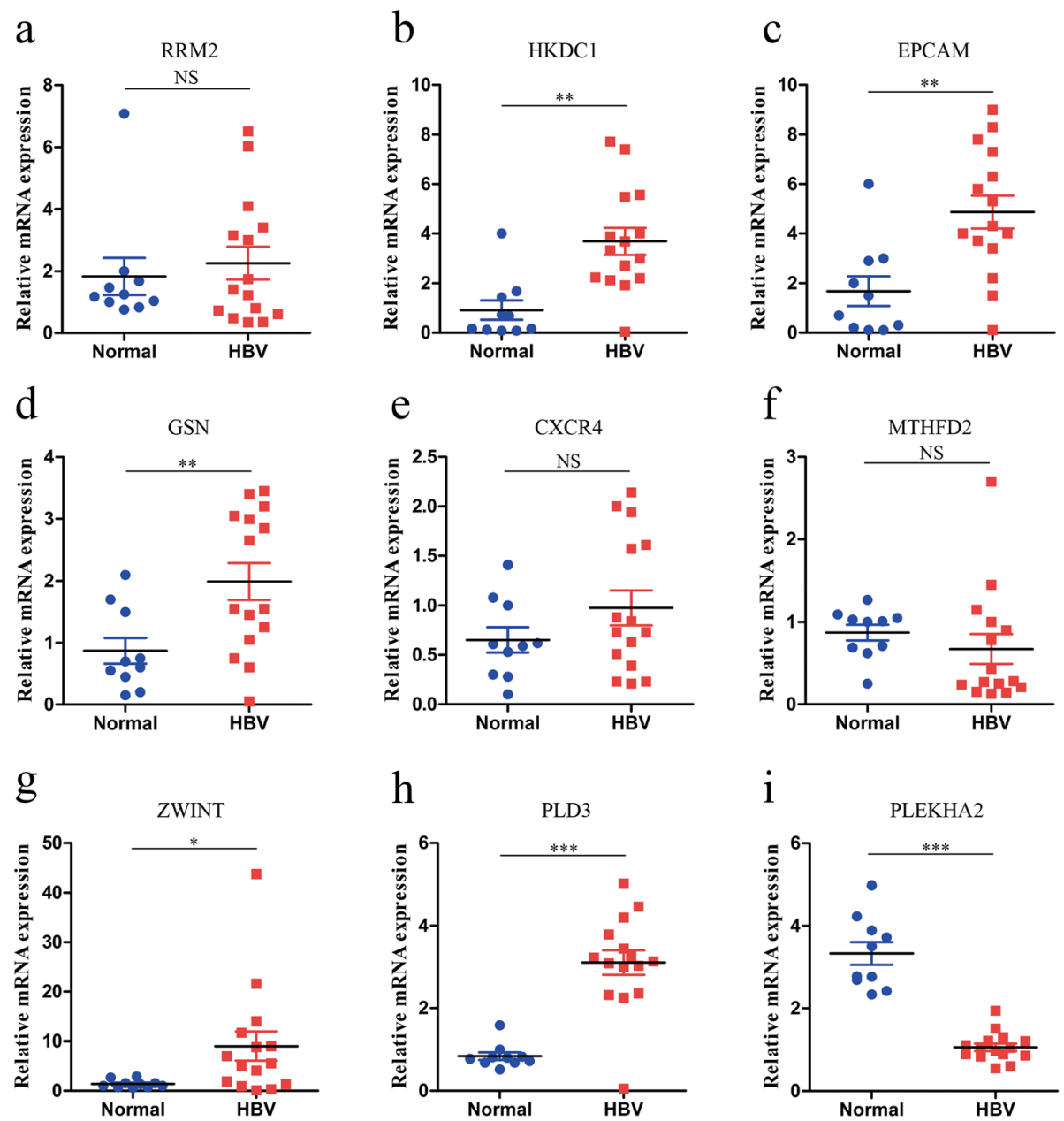

Fig. 4 a-i qRT-PCR validation of the 9 co-expressed DEGs in 15 HBV infected liver and 10 normal liver tissues. ${ }^{*} P<0.05,{ }^{* *} P<0.01,{ }^{* * *} P<0.001$, NS represents no significant differences, statistical analyses were performed using non-paired $t$ tests

regulated co-expressed DEGs, and PLEKHA2 was the down-regulated co-expressed DEG in 3 different cohorts. This indicates that the 9 genes are potential biomarkers for distinguishing the HBV infection and predicting responders of IFN- $\alpha$ based therapy. To further validation the data in clinical samples, the mRNA expression data showed that the 5 up-regulated DEGs (HKDC1, EPCAM, GSN, ZWINT and PLD3) were significantly increased and PLEKHA2 (the down-regulated DEG) was significantly decreased in HBV infected compared to the normal liver samples. It is known that RRM2 expression is essential for the synthesis of the HBV genomic DNA and cccDNA in the human liver cells, moreover, RRM2-targeting drugs constitute a novel category of candidates for the treatment of HBV-related diseases [18]. However, there were other evidence [19, 20] demonstrated that HBV induces the activation of the RRM2 expression selectively in nonproliferating cells. This may explain why the expression of RRM2 could not be verified in our clinical samples. Previous researches have shown that EPCAM plays a critical role in the process of the HBV-mediated hepatocarcinogenesis [21-23]. CXCR4, one of the chemokine receptors, function as a co-receptor for the T-cell line trophic strains of HIV-1. The expression of CXCR4 in the CD8 memory T cell may be used as biomarkers for predicting the outcomes of the treatment of the chronic HBV patients [24]. Wald's studies [25] suggest an important role for the CXCL12/CXCR4 pathway in the recruitment and retention of the immune cells in the liver during the chronic HCV and HBV infection. Although some literatures report that CXCR4 is closely related to HBV infection [24, 25], others [26] have shown the opposite effect. In a large case-control study, Jae Youn Cheong et al. reported that CXCR4 gene polymorphisms was not associated with the outcome of the HBV infection [26]. Therefore, the relations between CXCR4 gene and HBV infection remain controversial. It is reported that higher levels of urinary 8-oxo-GSN are more likely to have a high degree of fibrosis in the liver injury patients with HBV infection [27]. Previously, it has been shown that MTHFD2 
Table 2 Top 20 biological processes by GO BP analysis in 3 cohorts

\begin{tabular}{|c|c|c|c|}
\hline Rank & Cohort 1 & Cohort 2 & Cohort 3 \\
\hline 1 & immune response & immune response & small molecule metabolic process \\
\hline 2 & small molecule metabolic process & small molecule metabolic process & signal transduction \\
\hline 3 & inflammatory response & cell adhesion & immune response \\
\hline 4 & cell adhesion & inflammatory response & $\begin{array}{l}\text { positive regulation of transcription from RNA } \\
\text { polymerase II promoter }\end{array}$ \\
\hline 5 & signal transduction & signal transduction & negative regulation of apoptotic process \\
\hline 6 & negative regulation of apoptotic process & negative regulation of apoptotic process & transcription, DNA-dependent \\
\hline 7 & apoptotic process & $\begin{array}{l}\text { negative regulation of transcription, DNA- } \\
\text { dependent }\end{array}$ & innate immune response \\
\hline 8 & $\begin{array}{l}\text { negative regulation of transcription, DNA- } \\
\text { dependent }\end{array}$ & axon guidance & intracellular protein kinase cascade \\
\hline 9 & mitotic cell cycle & protein phosphorylation & virus-host interaction \\
\hline 10 & protein phosphorylation & protein complex assembly & apoptotic process \\
\hline 11 & protein complex assembly & response to virus & protein phosphorylation \\
\hline 12 & response to virus & blood coagulation & blood coagulation \\
\hline 13 & axon guidance & response to organic cyclic compound & $\begin{array}{l}\text { positive regulation of transcription, DNA- } \\
\text { dependent }\end{array}$ \\
\hline 14 & response to organic cyclic compound & mitotic cell cycle & positive regulation of apoptotic process \\
\hline 15 & regulation of immune response & regulation of immune response & $\begin{array}{l}\text { negative regulation of transcription from RNA } \\
\text { polymerase II promoter }\end{array}$ \\
\hline 16 & response to toxic substance & $\begin{array}{l}\text { negative regulation of transcription from RNA } \\
\text { polymerase II promoter }\end{array}$ & cell adhesion \\
\hline 17 & blood coagulation & chemotaxis & mitotic cell cycle \\
\hline 18 & chemotaxis & platelet activation & transmembrane transport \\
\hline 19 & $\begin{array}{l}\text { negative regulation of transcription from RNA } \\
\text { polymerase II promoter }\end{array}$ & apoptotic process & axon guidance \\
\hline 20 & dendritic cell chemotaxis & dendritic cell chemotaxis & positive regulation of cell migration \\
\hline
\end{tabular}

$G O$ gene ontology, BP biological process

[28] and ZWINT [29] are important oncogenes which are overexpressed in HCC and contribute to the progression of HCC. However, to our knowledge, there are no researches to show the relationship between MTHFD2 and HBV infection. Thus, the expression and function of MTHFD2 remain to be studied in larger clinical samples and HBV related disease models. These results imply that the abnormal co-expressed genes are involved in the progression of HBV to cirrhosis or liver cancer. Moreover, to validate the reliability of the microarray data, similar results were observed in qRT-PCR analyses in clinical samples in the current study.

From the pathway analysis, we identified the 8 aberrantly expressed signaling pathways in HBV infection. The activation of the PI3K-Akt signaling could regulate replication of the HBV in the liver cells [30], and also play an important role in promoting tumorigenesis of the HBV-associated HCC [31, 32]. Hepatitis B protein X was found to interact with the focal adhesion protein, that blocked the molecular linkage between the actin filament to weaken the intercellular adhesion [33, 34].
Chennari's study [35] indicated that the epidemiology of HTLV-I and HBV co-infection is related to the endemicity of HBV. In a systematic bioinformatic analysis, Tang et al. [36] found that the human La protein may play an important role in the development and progression of HBV through a cytokine-cytokine receptor interaction and other pathways. In primary rat hepatocytes, Lamontagne et al. [37] showed the metabolic consequences of an HBV infection, as a panel of 7 metabolites which were altered by $\mathrm{HBV}$ at different time points. A recent study demonstrated that activation of the NF- $\mathrm{kB}$ pathway causes inflammation and liver damage among patients with chronic HBV infection [38]. Changes in the chemokine levels following entecavir [39] or telbivudine [40] treatment are associated with response to antiviral therapy in chronic hepatitis $B$ patients. In the present study, we found that the PI3K-Akt signaling pathway, focal adhesion, HTLV-I infection, cytokinecytokine receptor interaction, metabolic pathways, NF$\kappa B$ signaling pathway, influenza $A$ and chemokine signaling pathway were the 8 common pathways related to 
Table 3 Top 20 pathways by KEGG pathway analysis in 3 cohorts

\begin{tabular}{|c|c|c|c|}
\hline Rank & Cohort 1 & Cohort 2 & Cohort 3 \\
\hline 1 & Chemokine signaling pathway & Chemokine signaling pathway & PI3K-Akt signaling pathway \\
\hline 2 & Cytokine-cytokine receptor interaction & Cytokine-cytokine receptor interaction & Influenza A \\
\hline 3 & Focal adhesion & Focal adhesion & Metabolic pathways \\
\hline 4 & PI3K-Akt signaling pathway & PI3K-Akt signaling pathway & Cytokine-cytokine receptor interaction \\
\hline 5 & HTLV-I infection & HTLV-I infection & Chemokine signaling pathway \\
\hline 6 & Metabolic pathways & Metabolic pathways & HTLV-I infection \\
\hline 7 & ECM-receptor interaction & Cell adhesion molecules (CAMs) & Herpes simplex infection \\
\hline 8 & Cell adhesion molecules (CAMs) & ECM-receptor interaction & Toxoplasmosis \\
\hline 9 & p53 signaling pathway & p53 signaling pathway & Hematopoietic cell lineage \\
\hline 10 & Rheumatoid arthritis & Amoebiasis & Protein processing in endoplasmic reticulum \\
\hline 11 & Viral carcinogenesis & Proteoglycans in cancer & NF-kappa B signaling pathway \\
\hline 12 & Amoebiasis & Viral carcinogenesis & Insulin signaling pathway \\
\hline 13 & Protein digestion and absorption & Rheumatoid arthritis & Leukocyte transendothelial migration \\
\hline 14 & Proteoglycans in cancer & Influenza A & Focal adhesion \\
\hline 15 & NF-kappa B signaling pathway & Protein digestion and absorption & Phagosome \\
\hline 16 & Cell cycle & Hepatitis B & Measles \\
\hline 17 & Pathways in cancer & NF-kappa B signaling pathway & Adipocytokine signaling pathway \\
\hline 18 & Toll-like receptor signaling pathway & Fc gamma R-mediated phagocytosis & Antigen processing and presentation \\
\hline 19 & Influenza A & Cell cycle & Adherens junction \\
\hline 20 & Hepatitis B & Malaria & Leishmaniasis \\
\hline
\end{tabular}

KEGG Kyoto Encyclopedia of Genes and Genomes

HBV infection. It is interesting to note that HTLV-1, influenza, measles etc. appear in the list of the top 20 in the 3 cohorts. The prevalence of HTLV-1 and HBV coinfection is high in certain indigenous Australian populations [41]. According to a population-based analysis [42], annual influenza vaccination can reduce the risk of hospitalization and mortality in patients with chronic HBV infection. It implies that the influenza-target therapy may have some effect on HBV infection. In a prospective study in diabetic children [43], the authors found a reduced efficacy of measles vaccination in the anti-HBs (-) patients, compared to the anti-HBs (+) patients. Thus, we can infer that there is an inherent correlation between HBV and measles. In the high endemic areas, $\mathrm{HBV}$ and $\mathrm{HCV} / \mathrm{HBV}$ and $\mathrm{HDV}$ co-infection is fairly common [44-46]. Although HCV and HDV infections have an important effect on the gene expression in co-infections with HBV, we didn't find HCV and HDV

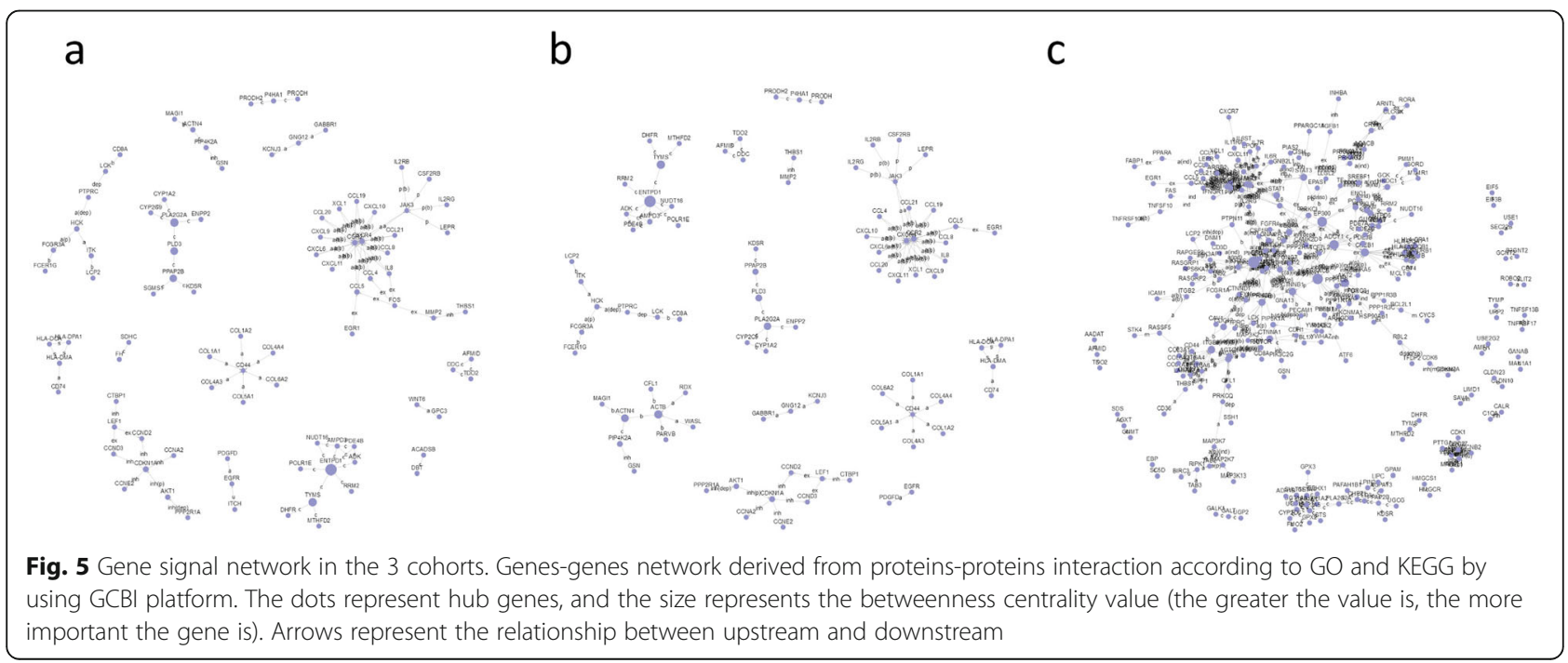


Table 4 Top 10 genes in gene signal network in 3 cohorts

\begin{tabular}{|c|c|c|c|}
\hline Rank & Gene symbol & Gene description & Degree \\
\hline \multicolumn{4}{|c|}{ Cohort 1} \\
\hline 1 & ENTPD1 & ectonucleoside triphosphate diphosphohydrolase 1 & 56 \\
\hline 2 & TYMS & thymidylate synthetase & 30 \\
\hline 3 & PLA2G2A & phospholipase A2, group IIA & 28 \\
\hline 4 & PLD3 & phospholipase D family, member 3 & 24 \\
\hline 5 & PPAP2B & phosphatidic acid phosphatase type $2 \mathrm{~B}$ & 22 \\
\hline 6 & CDKN1A & cyclin-dependent kinase inhibitor $1 \mathrm{~A}$ & 8 \\
\hline 7 & CCR2 & chemokine (C-C motif) receptor 2 & 7 \\
\hline 8 & CXCR4 & chemokine (C-X-C motif) receptor 4 & 7 \\
\hline 9 & AKT1 & v-akt murine thymoma viral oncogene homolog 1 & 5 \\
\hline 10 & CCL5 & chemokine (C-C motif) ligand 5 & 4 \\
\hline \multicolumn{4}{|c|}{ Cohort 2} \\
\hline 1 & ENTPD1 & ectonucleoside triphosphate diphosphohydrolase 1 & 56 \\
\hline 2 & TYMS & thymidylate synthetase & 30 \\
\hline 3 & ACTB & actin, beta & 28 \\
\hline 4 & ACTN4 & actinin, alpha 4 & 24 \\
\hline 5 & PLA2G2A & phospholipase A2, group IIA & 22 \\
\hline 6 & PLD3 & phospholipase D family, member 3 & 16 \\
\hline 7 & PPAP2B & phosphatidic acid phosphatase type $2 \mathrm{~B}$ & 10 \\
\hline 8 & CDKN1A & cyclin-dependent kinase inhibitor $1 \mathrm{~A}$ & 8 \\
\hline 9 & PIP4K2A & phosphatidylinositol-5-phosphate 4-kinase, type II, alpha & 7 \\
\hline 10 & CCR2 & chemokine (C-C motif) receptor 2 & 6.5 \\
\hline \multicolumn{4}{|c|}{ Cohort 3} \\
\hline 1 & PRKACB & protein kinase, cAMP-dependent, catalytic, beta & 18 \\
\hline 2 & EP300 & E1A binding protein $\mathrm{p} 300$ & 18 \\
\hline 3 & ADCY1 & adenylate cyclase 1 & 18 \\
\hline 4 & CREB1 & CAMP responsive element binding protein 1 & 17 \\
\hline 5 & STAT1 & signal transducer and activator of transcription 1 & 15 \\
\hline 6 & CTNNB1 & catenin (cadherin-associated protein), beta 1, $88 \mathrm{kDa}$ & 15 \\
\hline 7 & ITGB5 & integrin, beta 5 & 15 \\
\hline 8 & PRKCB & protein kinase $\mathrm{C}$, beta & 14 \\
\hline 9 & STAT3 & signal transducer and activator of transcription 3 & 12 \\
\hline 10 & AKT2 & v-akt murine thymoma viral oncogene homolog 2 & 10 \\
\hline
\end{tabular}

co-infection ranking in the top 20 DEGs. This may be explained by population differences and geographical distributions of the clinical samples. The issue still remains about how the co-expressed DEGs influence the pathways or other mechanisms in the progression of HBV infection in humans.

In our gene signal network analysis, we identified PLA2G2A, CXCR4, GNG12 and CXCL11 as the 4 common genes in the 3 cohorts. PLA2G2A is a key enzyme of the arachidonic acid synthases. A previous study [47] demonstrated that the serum levels of PLA2G2A are associated with the progression of HBV-related diseases, and HBV can upregulate the expression of PLA2G2A. Another study [48] found that CXCR4 was closely associated with the development of the HBV-related hepatitis. As compared to the healthy and asymptomatic HBV carriers, expression of CXCL10 and CXCL11 were elevated in patients with chronic active HBV and had positive correlation with ALT levels [49]. ENO1, TDO2, CXADR, MTHFD2 and PSME3 were 5 common genes identified in the gene connections analysis. Xiang Chun D. et al. found that ENO1 expression was upregulated in the HBV-infected liver tissues and cells; moreover, silencing ENO1 resulted in a significant reduction in HBV 


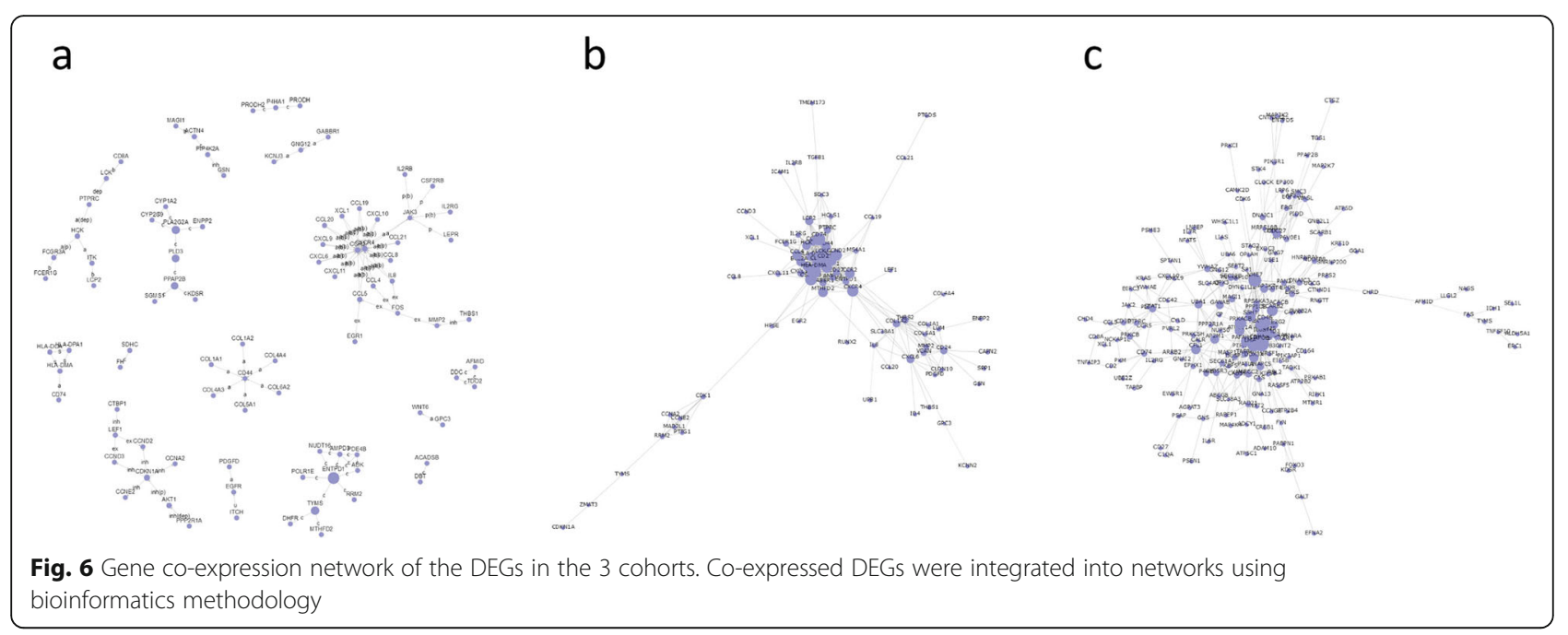

replication [50]. Additionally, we found that CD74, CCL5, CXCL10 and PTPRC were the 4 common genes in terms of the gene co-expression network. The serum level of CCL5 is a reliable marker that can predict disease progression in chronic hepatitis B patients [51]. The intrahepatic expression of CXCL10 was significantly increased in the HBeAg (+) compared to the HBeAg (-) patients [52]. And the upsurge of the serum HBV load significantly correlated with the increase of CXCL10 [53].

We acknowledge that there were some shortcomings and limitations in our study. First, we focused on the up-regulated and down-regulated genes without analyzing the contra-regulated genes. Second, we could not figure out if the interactions in the proteinprotein interaction network were direct or indirect. Additionally, we have not verified the DEGs in the liver specimen of IFN- $\alpha$ responders before/after treatment due to a lack of clinical cases in our center. It needs to be validated in an independent cohort to verify that these genes in the chronic HBV patients underwent IFN- $\alpha$ therapy. Further, though we conducted the validation of DEG expression, we did not validate the gene function or signaling pathways in clinical samples. Further studies considering these aspects are needed in the future.

\section{Conclusions}

To summarize, we used the GCBI bioinformatics analysis platform to study DEGs between HBV infected liver tissues and normal liver tissues, liver biopsy samples of IFN- $\alpha$ responders before and after treatment, which identified that 9 DEGs (8 up-regulated

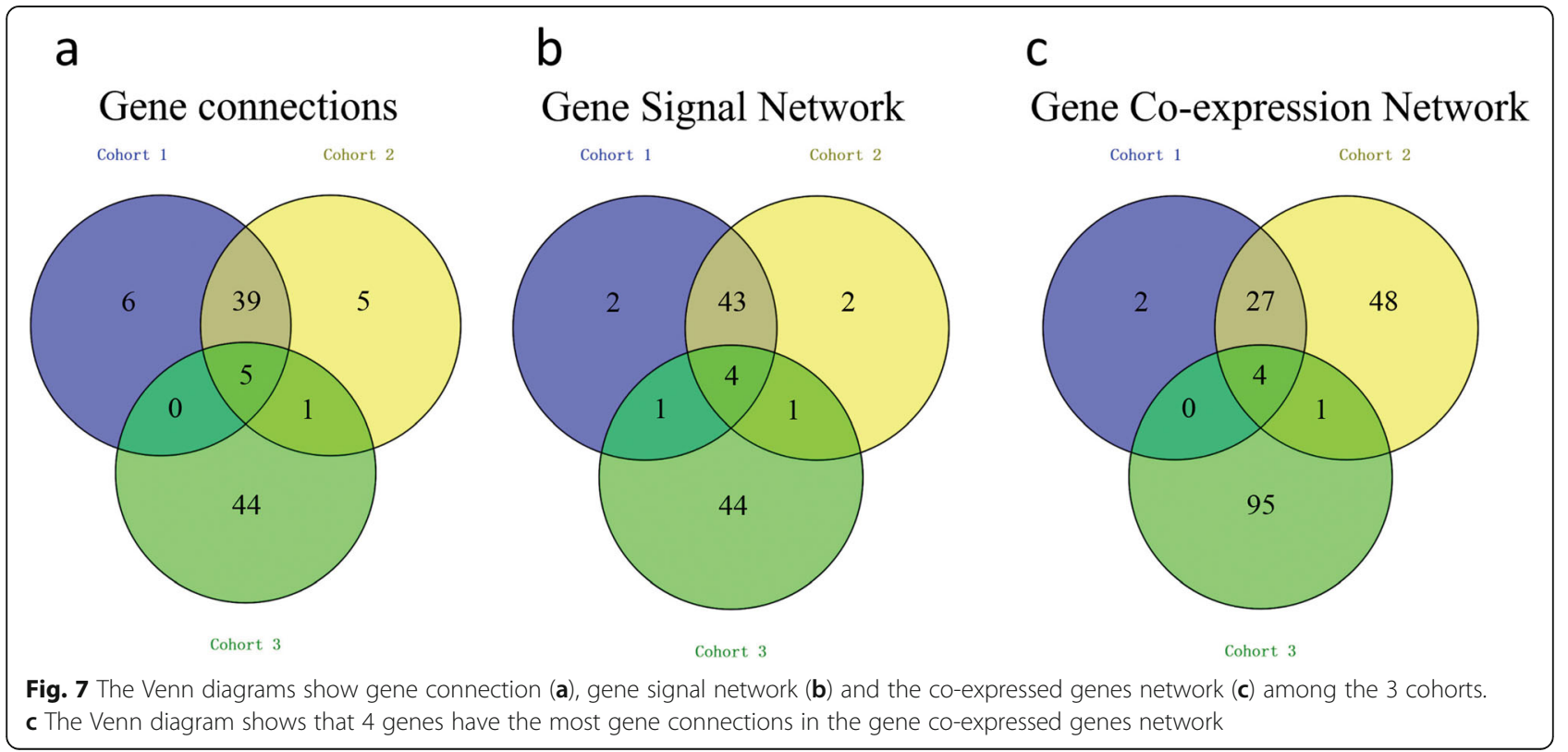


Table 5 Top 10 genes in gene co-expression network in 3 cohorts

\begin{tabular}{|c|c|c|c|}
\hline Rank & Gene symbol & Gene description & Degree \\
\hline \multicolumn{4}{|c|}{ Cohort 1} \\
\hline 1 & CD2 & CD2 molecule & 17 \\
\hline 2 & HLA-DMA & major histocompatibility complex, class II, DM alpha & 15 \\
\hline 3 & LCK & lymphocyte-specific protein tyrosine kinase & 14 \\
\hline 4 & CCND2 & cyclin D2 & 12 \\
\hline 5 & CD8A & CD8a molecule & 12 \\
\hline 6 & ITK & IL2-inducible T-cell kinase & 11 \\
\hline 7 & JAK3 & Janus kinase 3 & 11 \\
\hline 8 & CSF2RB & colony stimulating factor 2 receptor, beta, low-affinity & 10 \\
\hline 9 & RASGRP1 & RAS guanyl releasing protein 1 & 10 \\
\hline 10 & CXCR4 & chemokine (C-X-C motif) receptor 4 & 9 \\
\hline \multicolumn{4}{|c|}{ Cohort 2} \\
\hline 1 & HLA-DMA & major histocompatibility complex, class II, DM alpha & 28 \\
\hline 2 & CD2 & CD2 molecule & 28 \\
\hline 3 & CD74 & CD74 molecule, major histocompatibility complex, class II invariant chain & 26 \\
\hline 4 & CD8A & CD8a molecule & 24 \\
\hline 5 & CSF2RB & colony stimulating factor 2 receptor, beta, low-affinity & 24 \\
\hline 6 & LCK & lymphocyte-specific protein tyrosine kinase & 24 \\
\hline 7 & CCND2 & cyclin D2 & 23 \\
\hline 8 & JAK3 & Janus kinase 3 & 23 \\
\hline 9 & CXCR4 & chemokine (C-X-C motif) receptor 4 & 23 \\
\hline 10 & RASGRP1 & RAS guanyl releasing protein & 21 \\
\hline \multicolumn{4}{|c|}{ Cohort 3} \\
\hline 1 & APOB & apolipoprotein B & 26 \\
\hline 2 & NME7 & NME/NM23 family member 7 & 25 \\
\hline 3 & LMAN1 & lectin, mannose-binding, 1 & 24 \\
\hline 4 & $\mathrm{CDH} 1$ & cadherin 1, type 1, E-cadherin (epithelial) & 23 \\
\hline 5 & CD46 & CD46 molecule, complement regulatory protein & 23 \\
\hline 6 & PRKACB & protein kinase, cAMP-dependent, catalytic, beta & 22 \\
\hline 7 & SCARB2 & scavenger receptor class B, member 2 & 20 \\
\hline 8 & SSH1 & slingshot protein phosphatase 1 & 19 \\
\hline 9 & PAFAH1B1 & platelet-activating factor acetylhydrolase $1 \mathrm{~b}$, regulatory subunit 1 & 18 \\
\hline 10 & ABCB11 & ATP-binding cassette, sub-family B (MDR/TAP), member 11 & 18 \\
\hline
\end{tabular}

and 1 down-regulated DEGs) and 8 intersecting pathways in the relation network. Then, validation by qRT-PCR in the clinical samples, we concluded that the mRNA expression of 5 up-regulated DEGs was significantly increased and 1 down-regulated DEG was significantly decreased in $\mathrm{HBV}$ infected liver. These candidate genes and pathways might become therapeutic targets for $\mathrm{HBV}$ infection and further studies are required to elucidate the function and underlining mechanisms of these potential biomarkers in the progression of $\mathrm{HBV}$ infection.

\section{Supplementary information}

Supplementary information accompanies this paper at https://doi.org/10. 1186/s12879-019-4720-x.

Additional file 1: Table S1. General characteristics of 10 donors and 15 patients who underwent liver transplantation.

Additional file 2: Table S2. Sequence of primers used for validation of expression level of co-expressed DEGs.

\section{Abbreviations}

CAM: cell adhesion molecule; DEG: differentially expressed gene; ECM: extracellular matrix; EPCAM: epithelial cell adhesion molecule; 
GCBI: Gene-Cloud of Biotechnology Information; GEO: Gene Expression Omnibus; GO: gene ontology; HBV: hepatitis B virus; HCC: hepatocellular carcinoma; HTLV-I: human T-cell lymphotropic virus type 1; IFN-a: interferonalpha; KEGG: Kyoto Encyclopedia of Genes and Genomes; NCBI: National Center of Biotechnology Information; qRT-PCR: quantitative real time polymerase chain reaction; SPSS: Statistical Package for the Social Science; WHO: world health organization

\section{Acknowledgements}

Not applicable.

\section{Authors' contributions}

Conceived and designed the study: ZBZ, SZH, YXZ, QZ2 and XSH; Searched databases: ZBZ, CJS and YHT; Data analyses: SZH and YXZ; Preparation of tables and figures: QZ1 and WQJ; Wrote and revised the manuscript: ZBZ, $\mathrm{SZH}, \mathrm{YXZ}$ and XSH; All authors reviewed the manuscript. All authors read and approved the final manuscript.

\section{Funding}

This study was supported by the National Natural Science Foundation of China (81373156, 81471583 and 81570587), Guangdong Provincial international Cooperation Base of Science and Technology (Organ Transplantation) (2015B050501002), Guangdong Provincial Natural Science Funds for Major Basic Science Culture Project (2015A030308010), Pearl River Nova Program of Guangzhou (201506010014), the Science and Technology Program of Guangzhou (201704020150) and the Science and Technology Program of Huizhou (170520181743174). The funding bodies had no role in the design of the study and collection, analysis, and interpretation of data and in writing the manuscript.

\section{Availability of data and materials}

The GEO datasets (GSE83148, GSE84044 and GSE66698) analyzed in our study are directly available from GEO database (https:/www.ncbi.nlm.nih. gov/gds). Data are also available from the corresponding authors upon reasonable request.

\section{Ethics approval and consent to participate}

The First Affiliated Hospital of Sun Yat-sen University has reviewed and approved the research protocol. All procedures performed in studies involving human participants were in accordance with the ethical standards of the ethical committee of The First Affiliated Hospital of Sun Yat-sen University were obtained and with the 1964 Helsinki Declaration and its later amendments or comparable. All the livers were procured in Organ Transplant Center, The First Affiliated Hospital of Sun Yat-sen University. Hereby, we declare that no clinical biopsies were from executed prisoners. The written documentation of informed consent was obtained from every individual participant included in the study.

\section{Consent for publication}

Not applicable.

\section{Competing interests}

The authors declare that they have no competing interests.

\section{Author details}

'Organ Transplant Center, The First Affiliated Hospital of USTC, Division of Life Sciences and Medicine, University of Science and Technology of China, Hefei 230001, Anhui, China. ${ }^{2}$ Organ Transplant Center, The First Affiliated Hospital, Sun Yat-sen University, No. 58 Zhongshan Er Road, Guangzhou 510080, Guangdong, China. ${ }^{3}$ Department of General Surgery, Guangdong General Hospital, Guangdong Academy of Medical Sciences, Guangzhou 510030, Guangdong, China. ${ }^{4}$ Guangdong Provincial Key Laboratory of Organ Donation and Transplant Immunology, Guangzhou 510080, Guangdong, China. ${ }^{5}$ Guangdong Provincial International Cooperation Base of Science and Technology (Organ Transplantation), Guangzhou 510080, Guangdong, China. ${ }^{6}$ Department of General Surgery, Hui Ya Hospital of The First Affiliated Hospital, Sun Yat-sen University, Huizhou 516081, Guangdong, China. ${ }^{7}$ Department of Liver Surgery, The First Affiliated Hospital, Sun Yat-Sen University, Guangzhou 510080, Guangdong, China.

\section{Received: 8 November 2019 Accepted: 22 December 2019}

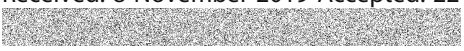

\section{References}

1. Tao J, Su K, Yu C, Liu X, Wu W, Xu W, et al. Fine mapping analysis of HLADP/DQ gene clusters on chromosome 6 reveals multiple susceptibility loci for HBV infection. Amino Acids. 2015;47(12):2623-34.

2. Schweitzer A, Horn J, Mikolajczyk RT, Krause G, Ott JJ. Estimations of worldwide prevalence of chronic hepatitis B virus infection: a systematic review of data published between 1965 and 2013. Lancet. 2015;386(10003): 1546-55.

3. Lavanchy D. Hepatitis B virus epidemiology, disease burden, treatment, and current and emerging prevention and control measures. J Viral Hepat. 2004; 11(2):97-107.

4. Trépo C, Chan HL, Lok A. Hepatitis B virus infection. Lancet. 2014;384(9959): 2053-63.

5. Perrillo R. Benefits and risks of interferon therapy for hepatitis B. Hepatology. 2009:49(5 Suppl):S103-11.

6. Lu X, Qin B, Ma Q, Yang C, Gong XY, Chen LM. Differential expression of ISG20 in chronic hepatitis B patients and relation to interferon-alpha therapy response. J Med Virol. 2013;85(9):1506-12.

7. Kong FY, Zhu T, Li N, Cai YF, Zhou K, Wei X, et al. Bioinformatics analysis of the proteins interacting with LASP-1 and their association with HBV-related hepatocellular carcinoma. Sci Rep. 2017;7:44017.

8. Zhou N, Wang K, Fang S, Zhao X, Huang T, Chen H, et al. Discovery of a potential plasma protein biomarker panel for acute-on-chronic liver failure induced by hepatitis B virus. Front Physiol. 2017;8:1009.

9. Lin H, Zhang Q, Li X, Wu Y, Liu Y, Hu Y. Identification of key candidate genes and pathways in hepatitis B virus-associated acute liver failure by bioinformatical analysis. Medicine (Baltimore). 2018;97(5):e9687.

10. Huang S, Sun C, Hou Y, Tang Y, Zhu Z, Zhang Z, et al. A comprehensive bioinformatics analysis on multiple gene expression omnibus datasets of nonalcoholic fatty liver disease and nonalcoholic steatohepatitis. Sci Rep. 2018;8(1):7630.

11. Zhou W, Ma Y, Zhang J, Hu J, Zhang M, Wang Y, et al. Predictive model for inflammation grades of chronic hepatitis B: large-scale analysis of clinical parameters and gene expressions. Liver Int. 2017;37(11):1632-41.

12. Wang M, Gong Q, Zhang J, Chen L, Zhang Z, Lu L, et al. Characterization of gene expression profiles in $\mathrm{HBV}$-related liver fibrosis patients and identification of ITGBL1 as a key regulator of fibrogenesis. Sci Rep. 2017;7: 43446.

13. Liaw YF, Leung N, Kao JH, Piratvisuth T, Gane E, Han KH, et al. Asian-Pacific consensus statement on the management of chronic hepatitis B: a 2008 update. Hepatol Int. 2008;2(3):263-83.

14. Wu HL, Hsiao TH, Chen PJ, Wong SH, Kao JH, Chen DS, et al. Liver gene expression profiles correlate with virus infection and response to interferon therapy in chronic hepatitis B patients. Sci Rep. 2016;6:31349.

15. Hatzakis A, Van Damme P, Alcorn K, Gore C, Benazzouz M, Berkane S, et al. The state of hepatitis $B$ and $C$ in the Mediterranean and Balkan countries: report from a summit conference. J Viral Hepat. 2013;20(Suppl 2):1-20.

16. Seeger C, Mason WS. Molecular biology of hepatitis B virus infection. Virology. 2015;479-480:672-86.

17. Li F, Li X, Zou GZ, Gao YF, Ye J. Association between copy number variations and hepatitis B virus infection outcome in Chinese. World J Gastroenterol. 2017;23(9):1602-7.

18. Liu X, Xu Z, Hou C, Wang M, Chen X, Lin Q, et al. Inhibition of hepatitis B virus replication by targeting ribonucleotide reductase M2 protein. Biochem Pharmacol. 2016;103:118-28.

19. Cohen D, Adamovich Y, Reuven N, Shaul Y. Hepatitis B virus activates deoxynucleotide synthesis in nondividing hepatocytes by targeting the R2 gene. Hepatology. 2010;51(5):1538-46.

20. Ricardo-Lax I, Ramanan V, Michailidis E, Shamia T, Reuven N, Rice CM, et al. Hepatitis B virus induces RNR-R2 expression via DNA damage response activation. J Hepatol. 2015;63(4):789-96.

21. Mani SK, Zhang H, Diab A, Pascuzzi PE, Lefrançois L, Fares N, et al. EpCAMregulated intramembrane proteolysis induces a cancer stem cell-like gene signature in hepatitis B virus-infected hepatocytes. J Hepatol. 2016;65(5): 888-98.

22. Kimura O, Kondo Y, Kogure T, Kakazu E, Ninomiya M, Iwata T, et al. Expression of EpCAM increases in the hepatitis B related and the treatmentresistant hepatocellular carcinoma. Biomed Res Int. 2014;2014:172913. 
23. Fan $H$, Zhang $H$, Pascuzzi PE, Andrisani O. Hepatitis B virus $X$ protein induces EpCAM expression via active DNA demethylation directed by RelA in complex with EZH2 and TET2. Oncogene. 2016;35(6):715-26.

24. Liu YZ, Hou FQ, Ding P, Ren YY, Li SH, Wang GQ. Pegylated interferon a enhances recovery of memory $T$ cells in e antigen positive chronic hepatitis B patients. Virol J. 2012:9:274.

25. Wald O, Pappo O, Safadi R, Dagan-Berger M, Beider K, Wald H, et al. Involvement of the CXCL12/CXCR4 pathway in the advanced liver disease that is associated with hepatitis C virus or hepatitis B virus. Eur J Immunol. 2004;34(4):1164-74.

26. Cheong JY, Cho SW, Choi JY, Lee JA, Kim MH, Lee JE, et al. RANTES, MCP-1, CCR2, CCR5, CXCR1 and CXCR4 gene polymorphisms are not associated with the outcome of hepatitis B virus infection: results from a large scale single ethnic population. J Korean Med Sci. 2007;22(3):529-35.

27. $X u X M$, Zhou XY, Li XY, Guo J, Wang HZ, Li Y, et al. Increased oxidative damage of RNA in liver injury caused by hepatitis B virus (HBV) infection. Free Radic Res. 2018;52(4):426-33.

28. Liu X, Huang $Y$, Jiang C, Ou H, Guo B, Liao H, et al. Methylenetetrahydrofolate dehydrogenase 2 overexpression is associated with tumor aggressiveness and poor prognosis in hepatocellular carcinoma. Dig Liver Dis. 2016;48(8):953-60.

29. Ying H, Xu Z, Chen M, Zhou S, Liang X, Cai X. Overexpression of Zwint predicts poor prognosis and promotes the proliferation of hepatocellular carcinoma by regulating cell-cycle-related proteins. Onco Targets Ther 2018;11:689-702

30. Rawat S, Bouchard MJ. The hepatitis B virus (HBV) HBx protein activates AKT to simultaneously regulate HBV replication and hepatocyte survival. J Virol. 2015:89(2):999-1012

31. Liu H, Xu J, Zhou L, Yun X, Chen L, Wang S, et al. Hepatitis B virus large surface antigen promotes liver carcinogenesis by activating the Src/PI3K/Akt pathway. Cancer Res. 2011;71(24):7547-57.

32. Karamitros T, Papatheodoridis G, Paraskevis D, Hatzakis A, Mbisa JL, Georgopoulou U, et al. Impact of interferon-a receptor-1 promoter polymorphisms on the transcriptome of the hepatitis B virus-associated hepatocellular carcinoma. Front Immunol. 2018;9:777.

33. Tan TL, Feng Z, Lu YW, Chan V, Chen WN. Adhesion contact kinetics of HepG2 cells during hepatitis B virus replication: involvement of $\mathrm{SH} 3$-binding motif in HBX. Biochim Biophys Acta. 2006:1762(8):755-66.

34. Lara-Pezzi E, Roche S, Andrisani OM, Sánchez-Madrid F, López-Cabrera M. The hepatitis $B$ virus $\mathrm{HBx}$ protein induces adherens junction disruption in a src-dependent manner. Oncogene. 2001;20(26):3323-31.

35. Chenari M, Norouzi M, Ghalichi L, Rezaee A, Yari A, Alavian SM, et al. Characterization of overt and occult hepatitis B virus infection among HTLV1 positive healthy carriers in the northeast of Iran; an HTLV-I endemic area. J Med Virol. 2014:86(11):1861-7.

36. Tang J, Zhang ZH, Liu GL. A systematic analysis of the predicted human La protein targets identified a hepatitis B virus infection signature. J Viral Hepat. 2013;20(1):12-23.

37. Lamontagne RJ, Casciano JC, Bouchard MJ. A broad investigation of the HBV-mediated changes to primary hepatocyte physiology reveals HBV significantly alters metabolic pathways. Metab Clin Exp. 2018;83:50-9.

38. Lin Y, Su C, Niu J, Guo Z, Lu Y. The association between NFKBIA polymorphisms and the progression of chronic hepatitis B virus infection among the Chinese Han population. Jpn J Infect Dis. 2018;71(1):21-7.

39. Kurihara M, Tsuge M, Murakami E, Mori N, Ohishi W, Uchida T, et al. The association between serum cytokine and chemokine levels and antiviral response by entecavir treatment in chronic hepatitis B patients. Antivir Ther. 2018;23(3):239-48

40. Liu C, Huang X, Werner M, Broering R, Ge J, Li Y, et al. Elevated expression of chemokine CXCL13 in chronic hepatitis B patients links to immune control during antiviral therapy. Front Immunol. 2017;8:323.

41. Turpin J, Yurick D, Khoury G, Pham H, Locarnini S, Melamed A, et al. Impact of hepatitis B virus coinfection on human T-lymphotropic virus type 1 clonality in an indigenous population of Central Australia. J Infect Dis. 2019; 219(4):562-7.

42. Su FH, Huang YL, Sung FC, Su CT, Hsu WH, Chang SN, et al. Annual influenza vaccination reduces total hospitalization in patients with chronic hepatitis $B$ virus infection: a population-based analysis. Vaccine. 2016;34(1):120-7.

43. Onal Z, Ersen A, Bayramoglu E, Yaroglu Kazancı S, Onal H, Adal E. Seroprotection status of hepatitis $B$ and measles vaccines in children with type 1 diabetes mellitus. J Pediatr Endocrinol Metab. 2016;29(9):1013-7.
44. Caccamo G, Saffioti F, Raimondo G. Hepatitis B virus and hepatitis C virus dual infection. World J Gastroenterol. 2014:20(40):14559-67.

45. Wedemeyer H, Manns MP. Epidemiology, pathogenesis and management of hepatitis D: update and challenges ahead. Nat Rev Gastroenterol Hepatol. 2010;7(1):31-40

46. Wu Q, Li Z, LiU Q. An important role of SREBP-1 in HBV and HCV coreplication inhibition by PTEN. Virology. 2018;520:94-102.

47. Zhu C, Song H, Shen B, Wu L, Liu F, Liu X. Promoting effect of hepatitis B virus on the expressoin of phospholipase A2 group IIA. Lipids Health Dis. 2017;16(1):5.

48. Zhu M, Lu Y, Li W, Guo J, Dong X, Lin B, et al. Hepatitis B virus X protein driven alpha fetoprotein expression to promote malignant behaviors of normal liver cells and hepatoma cells. J Cancer. 2016;7(8):935-46.

49. Lian JQ, Yang XF, Zhao RR, Zhao YY, Li Y, Zhang Y, et al. Expression profiles of circulating cytokines, chemokines and immune cells in patients with hepatitis B virus infection. Hepat Mon. 2014;14(6):e18892.

50. Xiang-Chun D, Xiao-Qing $Y$, Ting-Ting $Y$, Zhen-Hui $L$, Xiao-Yan $L$, Xia $L$, et al. Alpha-enolase regulates hepatitis $B$ virus replication through suppression of the interferon signalling pathway. J Viral Hepat. 2018;25(3):289-95.

51. Hu L, Zhu Y, Zhang J, Chen W, Li Z, Li L, et al. Potential circulating biomarkers of circulating chemokines CCL5, MIP-1 $\beta$ and HA as for early detection of cirrhosis related to chronic HBV (hepatitis B virus) infection. BMC Infect Dis. 2019;19(1):523.

52. Lebossé F, Testoni B, Fresquet J, Facchetti F, Galmozzi E, Fournier M, et al. Intrahepatic innate immune response pathways are downregulated in untreated chronic hepatitis B. J Hepatol. 2017:66(5):897-909.

53. Wu HL, Kao JH, Chen TC, Wu WH, Liu CH, Su TH, et al. Serum cytokine/ chemokine profiles in acute exacerbation of chronic hepatitis B: clinical and mechanistic implications. J Gastroenterol Hepatol. 2014;29(8):1629-36.

\section{Publisher's Note}

Springer Nature remains neutral with regard to jurisdictional claims in published maps and institutional affiliations.

\section{Ready to submit your research? Choose BMC and benefit from:}

- fast, convenient online submission

- thorough peer review by experienced researchers in your field

- rapid publication on acceptance

- support for research data, including large and complex data types

- gold Open Access which fosters wider collaboration and increased citations

- maximum visibility for your research: over $100 \mathrm{M}$ website views per year

At $\mathrm{BMC}$, research is always in progress.

Learn more biomedcentral.com/submissions 